\title{
Kütahya Merkez İlçesinde Sıvılaşma Potansiyelinin Coğrafi Bilgi Sistemi ile İncelenmesi
}

\section{Investigation of Liquefaction Potential in Kütahya Central District with Geographical Information System}

\author{
Tayfun Şengül $1^{*}$, Bahadır Karabaş² \\ Geliş / Received: 04/07/2021 \\ Kabul / Accepted: 10/08/2021
}

\begin{abstract}
ÖZ
Yeraltı su seviyesi yüksek, gevşek granüler veya alüvyon zeminlerin çevrimsel yükleme koşulları altında sıvılaşması, üst yapılarda onarılması mümkün olmayan hasarlara neden olmaktadır. Bu nedenle belirli bir bölgede yapılaşma öncesinde, sıvılaşma risk haritalarının oluşturulması önem kazanmaktadır. Bu çalışmada Kütahya ili Merkez ilçesinde yaklaşı $27 \mathrm{~km}^{2}$ 'lik bir alanda 61 farklı noktada ve her sondaj kuyusunun farklı derinliklerinde yapılmış Standart Penetrasyon Deney (SPT) sonuçları kullanılarak, Kütahya ve Simav fay zonlarında oluşabilecek deprem büyüklüğü $\mathrm{M}=6.5$, en büyük yerçekim ivmesinin $0.3 \mathrm{~g}$ olduğu kabul edilerek, farklı derinliklerde sıvılaşma risk haritaları oluşturulmuştur. Elde edilen analiz sonuçlarına göre, yeraltı su seviyesi yüzeye yakın, SPT-N değerlerinin düşük olduğu gevşek alüvyon zeminlerde sıvılaşma potansiyelinin yüksek olduğu belirlenmiştir. $\mathrm{Bu}$ çalışmada belirli bir bölgede için hazırlanan sıvılaşma risk haritalarının genişletilerek her türlü planlama faaliyetlerinde dikkate alınmasının faydalı olacağı değerlendirilmektedir.
\end{abstract}

Anahtar Kelimeler-Sivilaşma, Stvilaşma Potansiyel Haritaları, Standart Penetrasyon Deneyi

\begin{abstract}
The liquefaction of loose granular or alluvial soils with high groundwater levels under cyclic loading conditions causes irreparable damage to the superstructures. For this reason, it is crucial to create liquefaction risk maps before construction in a particular region. In this study, using the results of the Standard Penetration Tests (SPT) made at 61 different points and different depths of each borehole in an area of approximately $27 \mathrm{~km}^{2}$ in the central district of Kütahya, liquefaction risk maps were created at different depths. In the analyses, it was assumed that the earthquake magnitude which may occur in the Kütahya and Simav fault zones is $M=6.5$ and the greatest gravitational acceleration is $0.3 \mathrm{~g}$. According to the analyses results, it was determined that the liquefaction potential is high in loose alluvial soils where the groundwater level is close to the surface and the SPT-N values are low. In this study, it is considered that it would be beneficial to expand the liquefaction risk maps prepared for a particular region and take them into account in all kinds of planning activities.
\end{abstract}

\section{Keywords- Liquefaction, Liquefaction Potential Maps, Standard Penetration Test}

\footnotetext{
1*Sorumlu yazar iletişim: tayfun.sengul@dpu.edu.tr (https://orcid.org/0000-0003-3473-7724)

Inşaat Mühendisliği Bölümü, Kütahya Dumlupınar Üniversitesi, Evliya Çelebi Yerleşkesi, 43100 Kütahya, Türkiye

2İletişim: karabasbaha@gmail.com (https://orcid.org/0000-0003-0416-9121).

İnönü Üniversitesi, Mühendislik Fakültesi, İnşaat Mühendisliği Bölümü, Doktora Öğrencisi, 44280 Malatya, Türkiye
} 


\section{GíRiş}

Deprem büyüklüğü ve zamana bağlı olarak meydana gelen çevrimsel yükleme koşullarında, suya doygun gevşek kumlu ve siltli zeminlerin taşıma gücünü kısmen veya tamamen yitirmesi olarak adlandırılan sıvılaşma, son yıllarda geoteknik ve deprem mühendisleri için ilgi çekici ve karmaşık bir problem olmuştur. Sıvılaşma sonucu üst yapılar (binalar, köprüler v.b.), yollar ve hatta zemine gömülü boru hatları zarar görerek işlevlerini yapamaz hale gelebilirler. Bu nedenle herhangi bir sahada yapılaşma öncesi, o bölgenin yerel zemin koşulları ve deprem geçmişi göz önünde bulundurularak sıvılaşma potansiyeli belirlenmelidir. Zeminlerin sıvılaşma potansiyelinin belirlenmesinde birçok araştırmacı tarafından farklı yöntemler önerilmektedir [1-4].

Genel olarak zeminlerin sıvılaşma potansiyeli, araziden alınan örselenmemiş numuneler üzerinde laboratuvarda dinamik basit kesme ve dinamik üç eksenli basınç deneyleri yapılarak ya da arazide yapılan Standart Penetrasyon Deneyi (SPT), Koni Penetrasyon Deneyi, Kayma dalga hızı $\left(V_{s}\right)$ deneylerinden elde edilen verilerle belirlenebilmektedir. Arazide farklı derinliklerde örselenmemiş zemin numunesinin alınmasındaki zorluk, yüksek maliyet ve laboratuvarda sağlıklı dinamik deney sonuçlarının elde edilmesi gibi zorluklar, birçok araştırmacıyı arazi deneyleriyle ve özellikle SPT verileri ile sismik sıvılaşma analizi arasındaki ilişkiyi araştırmaya yöneltmiştir.

Günümüzde birçok araştırmacı farklı bölgeler için, sismik tehlike analizi üzerinde çalışarak en büyük yer ivmesi ve spektral ivme haritaları, Coğrafi Bilgi Sistemi (CBS) tabanlı programlar vasıtasıyla sıvılaşma riski yüksek bölgelerin haritalarını üretmişlerdir. Ayrıca SPT verileri ile sismik sıvılaşma analizi arasındaki ilişki araştırılmıştır [4-5].

Bu çalışmada, arazide yaygın olarak veri elde etmek için kullanılan SPT verileri ve laboratuvar deney sonuçları dikkate alınarak Youd ve diğ. [6] yöntemine göre, Kütahya şehir merkezinde belirli bir bölgede zeminlerin sıvılaşma potansiyeline yönelik analizler yapılmıştır. Bu analizler sonucunda, bölgede oluşabilecek deprem büyüklüğ̈̈ $\mathrm{M}=6.5$, en büyük yerçekim ivmesinin $0.3 \mathrm{~g}$ olduğu kabul edilerek, farklı derinliklerde $(0-3,3$ 6, 6-9, 9-12 m) sıvılaşma potansiyeli haritaları CBS tabanlı bir bilgisayar yazılımı kullanılarak oluşturulmuştur.

\section{INCELEME ALANININ COĞRAFI KONUMU VE JEOLOJISİ}

İnceleme alanı, Kütahya İli Merkez ilçesindeki yaklaşık $27 \mathrm{~km}^{2}{ }^{2}$ lik sahayı temsil etmektedir. Ege Bölgesi'nin kuzeydoğusunda yer alan Kütahya ili, kuzeybatı ve kuzeyde Bursa, Kuzeyde Bilecik, kuzeydoğu ve doğuda Eskişehir, doğu ve güneydoğuda Afyon, güneyde Uşak, güneybatı ve batıda Manisa, batıda ise Balıkesir ile çevrilir.

Denizden yüksekliği 970 m olan Kütahya ili Ege bölgesinin kuzey doğusunda yer almaktadır. Kütahya ili Merkez ilçesinin yerleşimi kuzeybatı-güneydoğu doğrultusunda olup Kütahya ovasına paraleldir. Neojen ve yaşlı alüvyon olan Kuvaterner çökelleri üzerinde bulunan inceleme sahası, güneyde çamurtaş1, silttaş1, kumtaşı ve çakıltaşından oluşan Kıyır Formasyonu ve kuzeyde ise çamurtaşı, kiltaşı, kumtaşı ve çakılltaşından oluşan Çöğürler Formasyonu tarafından çevrelenmektedir. İnceleme sahasının yer bulduru haritası Şekil 1'de gösterilmektedir.

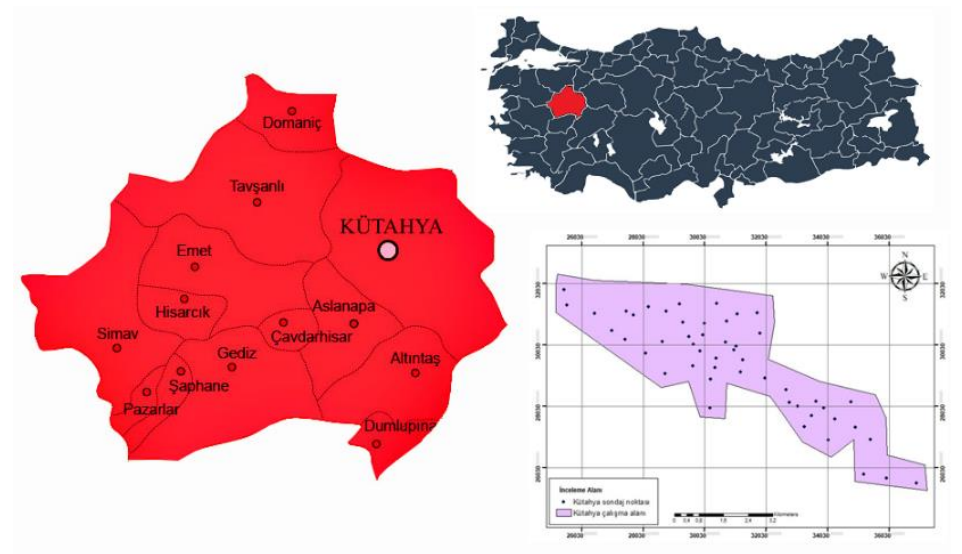

Şekil 1. Yer bulduru haritası 


\begin{tabular}{|c|c|c|}
\hline & $\begin{array}{l}\text { BŞEÜ Fen Bilimleri Dergisi } \\
8(2), 817-825,2021\end{array}$ & $\begin{array}{r}\text { BSEU Journal of Science } \\
\text { https://doi.org/10.35193/bseufbd.962190 }\end{array}$ \\
\hline $\begin{array}{l}\text { BILECEIKSEYH EDEBALI } \\
\text { ONIVERSITES }\end{array}$ & & 2458-7575 (https://dergipark.org.tr/tr/pub/bseufbd) \\
\hline
\end{tabular}

\section{III. İNCELEME ALANININ DEPREMSELLİĞI}

Ege bölgesinde yer alan Kütahya ili ve inceleme alanı Şekil 2.'de sunulan Kütahya ve Simav fay zonlarının etkisi altındadır. Kütahya merkez ilçesi ve çevresinde yakın geçmişteki deprem etkinlikleri, dünyada deprem istasyonlarının yaygınlaştı̆ı 1900 yılı sınır kabul edilmek suretiyle 1900 yılı sonrası depremler için incelenmiştir. AFAD veri tabanının incelenmesi neticesinde 1900-2020 yılları arasında büyüklüğü 4.0'den büyük olmak üzere, 325 deprem meydana geldiği görülmüsşür. Bu depremlerden ikisi büyüklüğü 6 ve üzeri güçlü ve şiddetli, 25'i büyüklüğ̈̈ 5 ve üzeri orta büyüklüklü olan deprem grubundadır. Söz konusu depremlerin yaklaşık alan dağılımı Şekil 3.'de ve bu tarih diliminde büyüklük olarak ilk 10 sırada yer alan depremler Tablo 1.'de sunulmuştur. İnceleme sahasına en yakın ve büyüklük olarak en önemli deprem, 28.03.1970 tarihinde meydana gelen 7.2 M büyüklüğünde gerçekleşen ve 1086 kişinin hayatının kaybetmesi ile sonuçlanan Gediz depremidir [7]. Söz konusu fayların etkisinde olan inceleme alanında en büyük yerçekim ivmesinin ortalama $0.3 \mathrm{~g}$ olduğu AFAD veri tabanının incelenmesi neticesinde tespit edilmiş ve sıvılaşma analizlerinde bu değer kullanılmıştır.

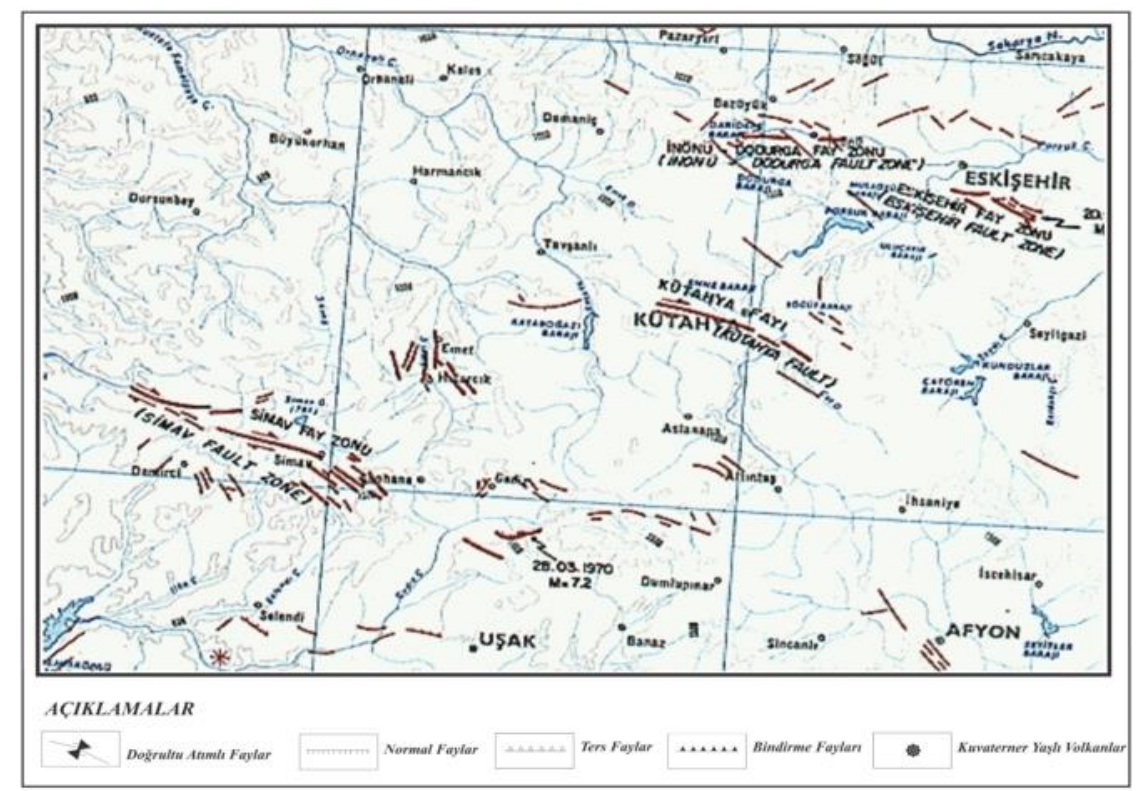

Şekil 2. İnceleme alanı ve yakın çevresindeki yer alan fayları gösterir harita [8]

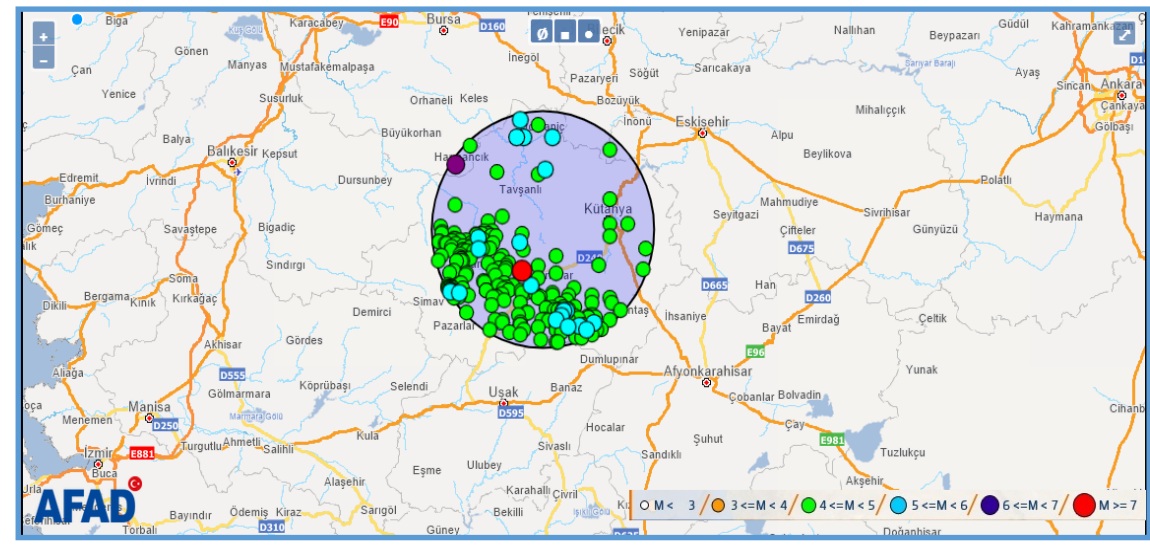

Şekil 3. Kütahya merkez ilçesi ve çevresinde 1900-2020 yılları arasında $M \geq 4.0$ depremlerin dağılımı [9] 


\begin{tabular}{|c|c|c|}
\hline & $\begin{array}{l}\text { BŞEÜ Fen Bilimleri Dergisi } \\
8(2), 817-825,2021\end{array}$ & $\begin{array}{r}\text { BSEU Journal of Science } \\
\text { https://doi.org/10.35193/bseufbd.962190 }\end{array}$ \\
\hline $\begin{array}{l}\text { BILLECKS SEYHEDEBALI } \\
\text { UNIVERSITESI }\end{array}$ & & 2458-7575 (https://dergipark.org.tr/tr/pub/bseufbd) \\
\hline
\end{tabular}

Tablo 1. Kütahya merkez ilçesi ve çevresinde ve 1900-2020 yılları arasında meydana gelen önemli depremler

\begin{tabular}{cccccc}
\hline Numara & Tarih & Enlem & Boylam & Derinlik (km) & Büyüklük \\
\hline $\mathbf{1}$ & 28.03 .1970 & 39.2100 & 29.5100 & 18.00 & 7.2 \\
\hline $\mathbf{2}$ & 02.05 .1928 & 39.6400 & 29.1400 & 10.00 & 6.1 \\
\hline $\mathbf{3}$ & 19.05 .2011 & 39.1328 & 29.0820 & 24.46 & 5.9 \\
\hline $\mathbf{4}$ & 19.04 .1970 & 38.9820 & 29.7670 & 14.80 & 5.6 \\
\hline $\mathbf{5}$ & 14.03 .1972 & 39.3250 & 29.4970 & 41.40 & 5.5 \\
\hline $\mathbf{6}$ & 25.05 .1971 & 39.0260 & 29.7300 & 11.80 & 5.5 \\
\hline $\mathbf{7}$ & 19.04 .1970 & 38.9860 & 29.8290 & 17.60 & 5.5 \\
\hline $\mathbf{8}$ & 25.06 .1944 & 38.9700 & 29.8700 & 40.00 & 5.5 \\
\hline $\mathbf{9}$ & 24.04 .1970 & 39.0100 & 29.7000 & 44.00 & 5.3 \\
$\mathbf{1 0}$ & 28.03 .1970 & 39.5000 & 30.3000 & 33.00 & 5.3 \\
\hline
\end{tabular}

\section{ARAZİ VERÍLERİ VE YÖNTEM}

\section{A. Arazi Verileri}

Çalışma alanında derinliği 3.0-20.0 m arasında değiş̧en 61 adet sondaj kuyusu açıllmış olup bu sondajların toplam uzunluğu 763.6 m'dir. Sondaj kuyularında farklı derinliklerde gerçekleştirilen 455 adet SPT deneyleriyle arazi incelenmiş aynı zamanda örselenmiş ve örselenmemiş numuneler alınarak laboratuvarda zeminin fiziksel ve mekanik özellikleri belirlenmiştir. Sondaj kuyularının her birinde yeraltı su seviyesinin konumu tespit edilmiştir. İnceleme sahasındaki zemin türlerinin derinlikle değiş̧imi Şekil 4'te gösterilmektedir.
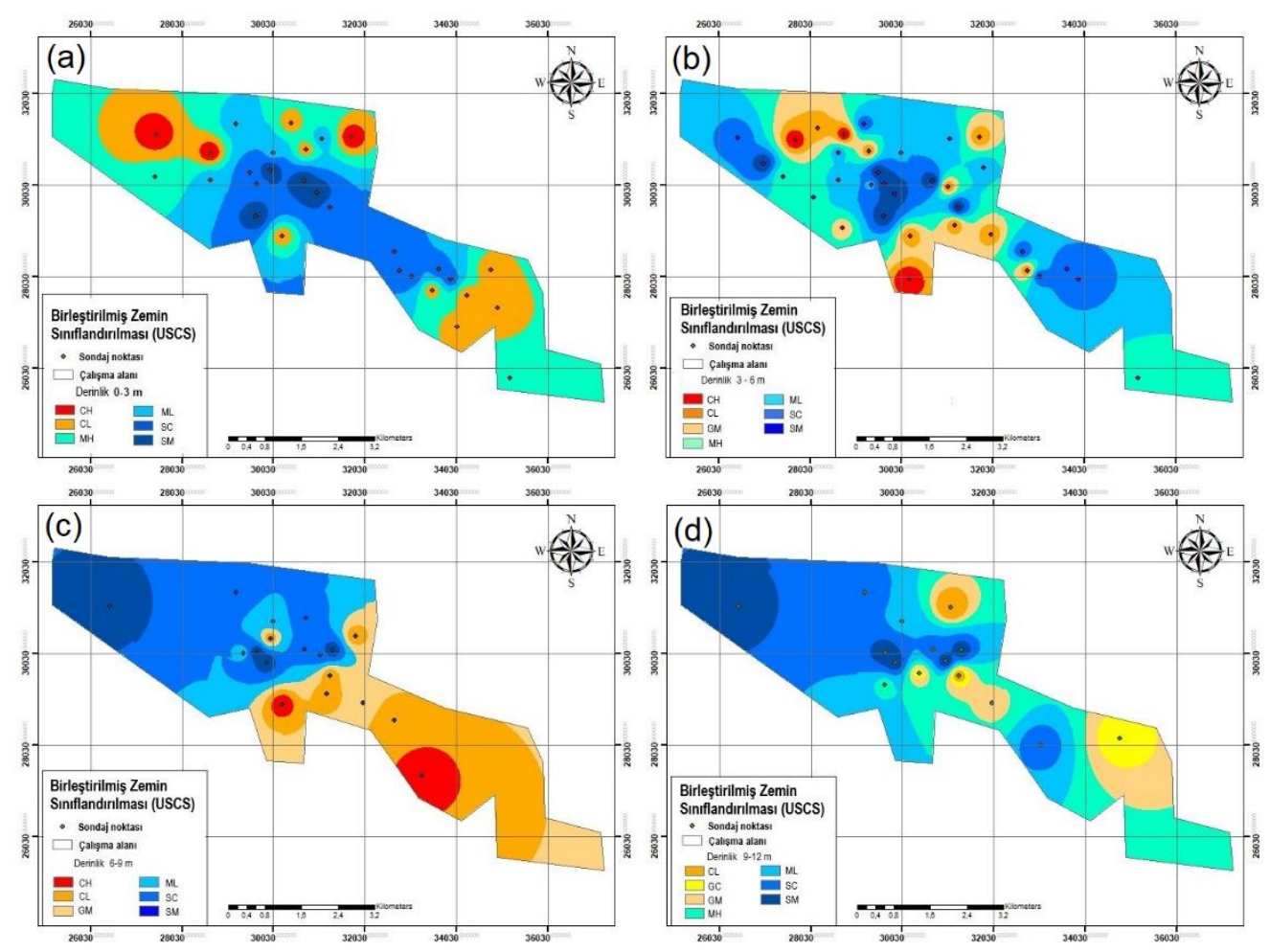

Şekil 4. (a) İnceleme sahasındaki zemin türlerinin 0-3 m derinlikteki dağılımı, (b) 3-6 m derinlikteki dağılımı, (c) 6-9 m derinlikteki dağılımı, (d) 9-12 m derinlikteki dağılımı 
İnceleme sahasındaki zemin örnekleri Neojen örtü ve alüvyon zeminlerden oluşmaktadır. Elek analizi deney sonuçları çalışma analındaki tüm zemin örneklerinin \%43'ünün iri daneli \%57'sinin ise ince daneli zemin olduğunu göstermektedir. Düşük plastisiteli Kil ve Silt zemin türleri daha yaygın olup, yüksek plastisiteli kil zeminler daha bölgesel olarak görülmektedir. İri daneli zeminlerde ise killi ve siltli kum zeminler hakim zemin tipi olup çakıl zeminler iri daneli zemin grubunun sadece \%16'sını oluşturmaktadır.

Zeminlerin plastisite özellikleri incelendiğinde, likit limit (LL) değerinin 21-93, plastisite indeksi (PI) değerinin 2-54 aralığında değiştiği zeminlerin büyük bir çoğunluğunun düşük plastisiteli olduğu görülmektedir.

\section{B. SPT-N Dĕgerleri}

Standart Penetrasyon Deneyi (SPT) geoteknik çalışmalarda yaygın olarak kullanılan arazi deneyidir. Çalışma alanında, yüzeyden itibaren $12 \mathrm{~m}$ derinliğe kadar SPT-N değerlerinin dağılımını ve derinlik artışı ile birlikte değişimini görebilmek amacıyla 0-3 m, 3-6 m, 6-9 m, 9-12 m derinlikleri için haritalar oluş̧urulmuştur. Haritalar oluşturulurken SPT-N değerleri tahmini haritaları $10 \mathrm{~m}$ karelaj boyutlu olarak üretilmiş, 1 ile 50 arası değerler tespit edilmiştir. İnceleme sahasındaki SPT-N değerlerinin, derinlikle değişimi haritaları Şekil 5 'te gösterilmektedir.
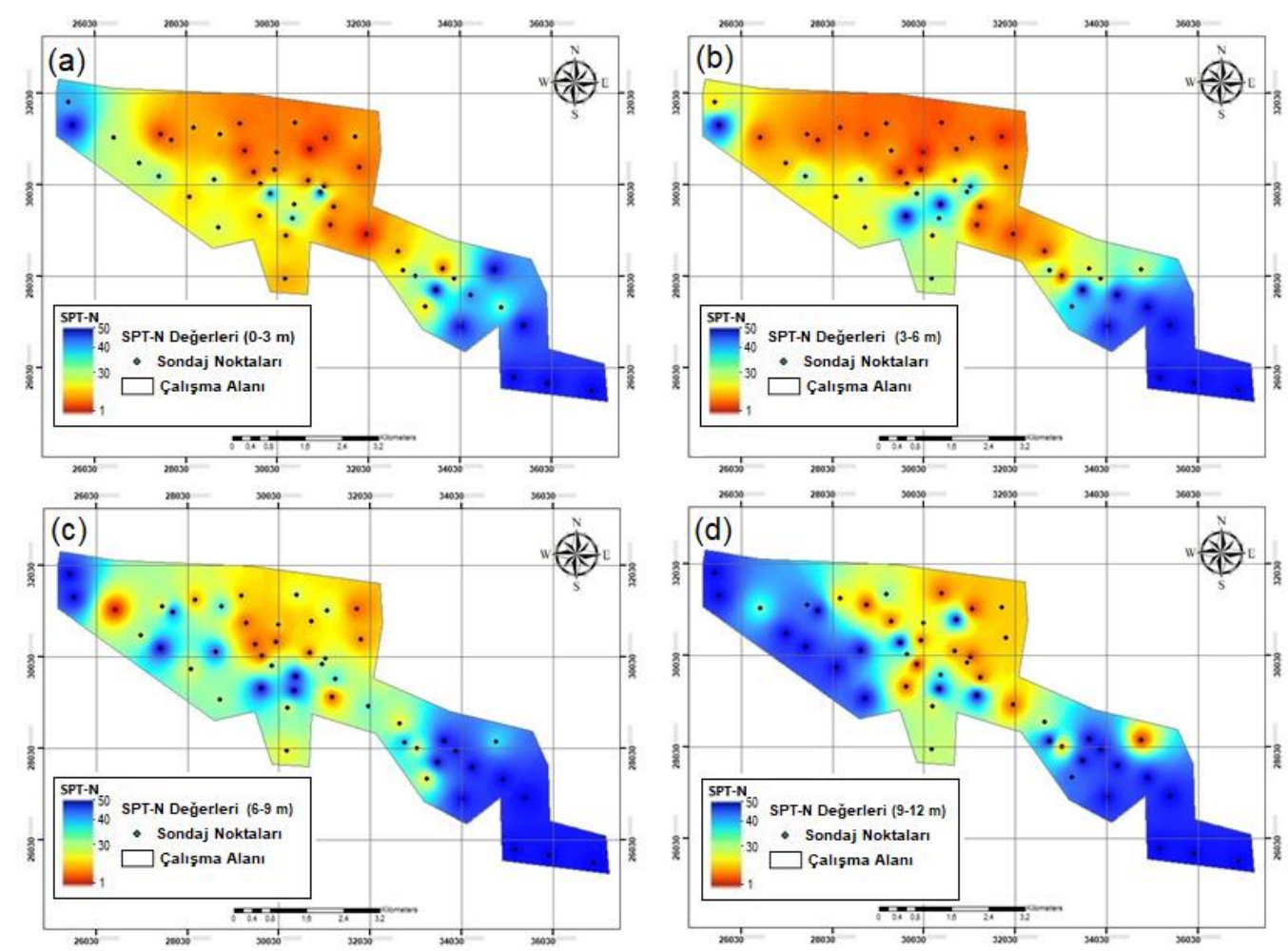

Şekil 5. (a) İnceleme sahasındaki SPT-N değerlerinin 0-3 m aralığında derinlikle değişimi, (b) 3-6 m aralığında derinlikle değişimi, (c) 6-9 m aralığında derinlikle değişimi, (d) 9-12 m aralığında derinlikle değişimi

Farklı zemin türlerinin bulunduğu çalışma alanında, en düşük SPT darbe sayıları inceleme sahasının kuzeyi ile kuzey batı doğrultusu arasındaki bölgede görülmektedir. Bu bölgede 0-3 m derinlikte yapılan sondajlarda elde edilen SPT darbe sayıları 0-10 arasında olmakla birlikte, bölgenin büyük bir kısmında 5'den küçüktür. Bölgedeki zemin türleri, çok yumuşak ve orta katı kıvamda olan düşük plastisiteli kil (CL) ve düşük plastisiteli silt (ML) ve çok gevşek ve gevşek siltli kum (SM) ve killi kumdan (SC) oluşmaktadır. Bölgenin genel jeolojisi Neojen ve Kuvaterner yaşlı birimler olup, arazide dikkate değer miktarda alüvyon malzeme stokunun varlığ sıvılaşma potansiyelini beraberinde getirmektedir.

3-6 m derinlikte yapılan sondajlarda elde edilen SPT darbe sayıları genel olarak aynı bölge için 6-15 arasında değişmekte iken, 6 m'den daha derinde bu değer giderek artmaktadır. 


\section{Yeralt Su Seviyesi}

Çalışma alanı genelinde 61 sondaj noktasından elde edilen verilere göre yeraltı suyuna 1 ve $10 \mathrm{~m}$ arasında 25 sondaj noktasında rastlanmıştır. Çalışma alanının \%34'ünde 1-5 m, \%16'sında 6-12 m, \%50'sinde 13 m'den daha büyük derinlikte yeraltı su seviyesinin olduğu değerlendirilmektedir. Bu kapsamda hazırlanan araştırma alanında yeraltı su seviyesinin derinlikle değişimini gösteren harita Şekil 6'da sunulmaktadır.

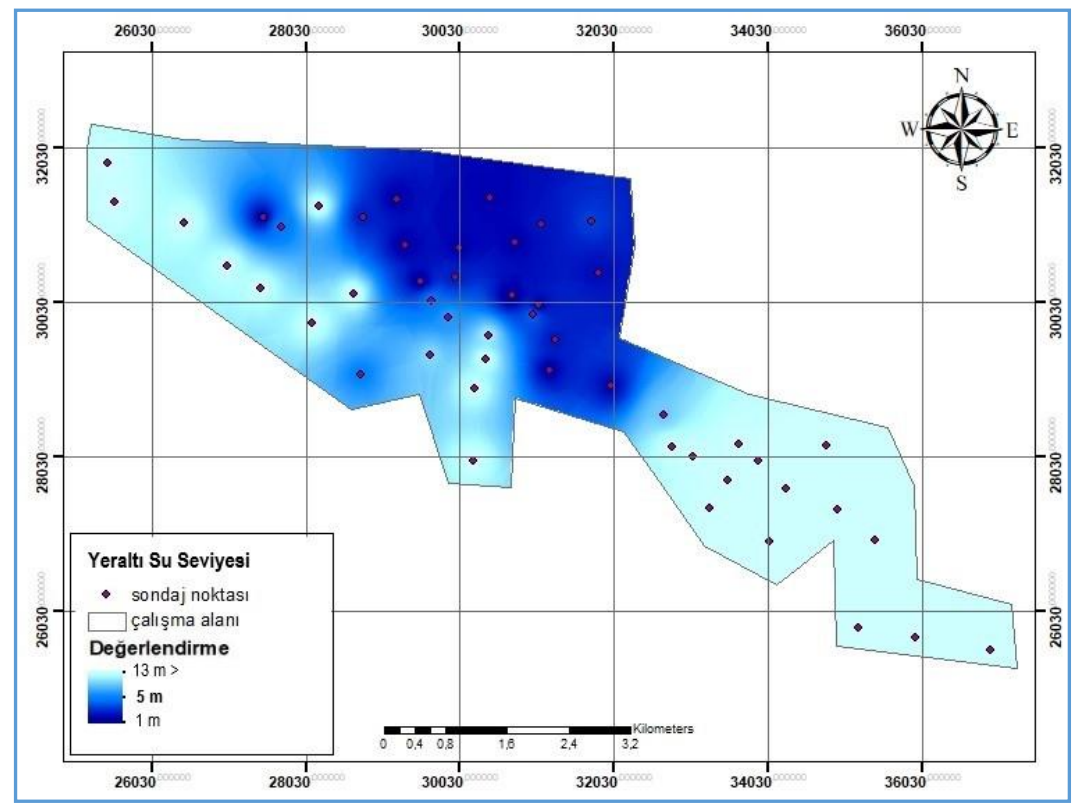

Şekil 6. Yeraltı su seviyesi

İnceleme sahasının kuzeyi ile kuzey batı doğrultusu arasındaki bölgede genel olarak SPT-N değerlerinin düşük olması bu bölgedeki yer altı su seviyesinin yüzeye yakın bir bölgede olduğunun bir göstergesidir. Bölgede yeraltı su seviyesi 1.0-3.0 m arasında değişen seviyelerde bulunmaktadır. Hakim zeminin silt, silttli kum, killi kum gibi zeminlerden oluşması, suya doygun olması ve aynı zamanda bu bölgede zeminlerin gevşek olması sıvılaşmanın gerçekleşebilmesi için uygun ortamı sağlamaktadır.

İnceleme sahasının kuzey batı doğrultusunun dışındaki yakın bölgelerde yeraltı suyu seviyesi kademeli olarak derinleşerek 5.0-10.0 m aralığında görülmektedir. Çok sıkı, katı-sert zeminlerden oluşan daha uzak bölgelerde ise $12.0 \mathrm{~m}$ derinliğe kadar yeraltı su seviyesinin varlığı gözlenmemiş̧tir.

\section{Yöntem}

Sıvılaşma fenomeni, dinamik yüklemeye maruz kalan kohezyonsuz zeminlerde kayma mukavemetinin kısmen veya tamamen, hızlı bir şekilde kaybına ve dolayısıyla üst yapılarda telafisi mümkün olmayan hasarlara neden olmaktadır.

Zeminlerin sıvılaşma potansiyelini belirlemek için saha ve laboratuvar deneylerini temel alan birçok analiz yöntemi bulunmaktadır. Laboratuvar deneylerinin tatbik güçlükleri, zaman alıcı ve maliyetli olması nedeniyle, saha deneylerini sıvılaşma potansiyeli araştırmalarında daha etkin kılmaktadır. Bu kapsamda SPT deney sonuçları kullanılarak amprik hesaplama yöntemleri ile sıvılaşma potansiyeli tespitleri yapılmaktadır. Amprik analizlerin çoğu, deprem yükünü döngüsel gerilim oranı cinsinden tanımlayan döngüsel gerilim yaklaşımını kullanır. Bu çalışmada, inceleme sahasında farklı deriliklerde zeminlerin sıvılaşma potansiyelleri Youd ve diğ., 2001 tarafından önerilen zeminin sıvılaşmaya karşı döngüsel direnç oranının (CRR), depremin oluşturduğu döngüsel gerilim oranıyla (CSR) kıyaslanarak belirlenmeye çalışılmıştır. Depremin oluşturduğu döngüsel gerilim oranı (CSR) Denklem (1) ile hesaplanmaktadır.

$$
\operatorname{CSR}=\left(\tau_{\text {av }} / \sigma_{\text {vo }}^{\prime}=0.65 *\left(a_{\text {maks }} / g\right) *\left(\sigma_{\text {vo }} / \sigma_{\text {vo }}^{\prime}\right) * r_{d}\right.
$$


CSR: depremin oluşturduğu döngüsel gerilim oranı, amaks: en büyük yer ivmesi ( $\left.\mathrm{cm} \mathrm{sec}^{-2}\right)$, g: yerçekim ivmesi $\left(\mathrm{cm} \mathrm{sec}^{-2}\right), \sigma_{\mathrm{vo}}$ : düşey toplam gerilme $(\mathrm{kPa}), \sigma_{\mathrm{vo}}^{\prime}$ : düşey efektif gerilme $(\mathrm{kPa}), \mathrm{r}_{\mathrm{d}}$ : gerilim azaltma faktörü'dür. $[10]$.

Gerilim azaltma faktörü $\left(\mathrm{r}_{\mathrm{d}}\right.$ ) derinlikle değişen bir faktördür Denklem (2) ve Denklem (3) ile hesaplanır

$$
\begin{aligned}
& \mathrm{z} \leq 9.15 \mathrm{~m} \text { için } \mathrm{r}_{\mathrm{d}}=1.0-0.00765 \mathrm{z} \\
& 9.15<\mathrm{z} \leq 23 \mathrm{~m} \text { için } \mathrm{r}_{\mathrm{d}}=1.174-0.00267 \mathrm{z}
\end{aligned}
$$

Zeminin sıvılaşmaya karşı döngüsel direnç oranı olarak ifade edilen CRR, düzeltilmiş SPT darbe sayısı $\mathrm{N}_{1(60)}$ ile granüler zeminlerde ince dane oranının $\% 5$ ya da daha az, $\% 15$ ve $\% 35$ olması durumları için döngüsel gerilim oranı arasındaki korelasyonla belirlenir.

SPT deneyinin yapıldı̆̆ı derinlikler için düzeltilmiş darbe sayıları $\mathrm{N}_{1(60)}$ Denklem (4) kullanılarak belirlenmiştir [6].

$$
\left(\mathrm{N}_{1}\right)_{60}=\mathrm{N} \cdot \mathrm{C}_{\mathrm{N}} \cdot \mathrm{C}_{\mathrm{E}} \cdot \mathrm{C}_{\mathrm{B}} \cdot \mathrm{C}_{\mathrm{R}} \cdot \mathrm{C}_{\mathrm{S}}
$$

Bu eşitlikte; $N$ : düzeltilmemiş $S P T$ darbe sayısı, $C_{N}$ : jeolojik yük düzeltmesi, $C_{E}$ : enerji düzeltmesi, $C_{B}$ : sondaj çapı düzeltmesi, $C_{R}$ : tij uzunluğu düzeltmesi ve $C_{S}$ : numune alıcı kılıf (tüp) düzeltmesidir. Jeolojik yük düzeltmesi $\left(C_{N}\right)$ Denklem (5) ile, Donut tipi şahmerdanın enerji oranı (Er) \%45 için enerji düzeltmesi $\left(C_{E}\right)$ Denklem (6) ile belirlenmiştir.

$$
\mathrm{C}_{\mathrm{N}}=2.2 /\left(1.2+\left(\sigma_{\mathrm{vo}}^{\prime} / \mathrm{Pa}\right)\right)
$$

Bu eşitlikte, $\mathrm{P}_{\mathrm{a}}$ : atmosferik basınç $(100 \mathrm{kPa}), \sigma_{\mathrm{vo}}^{\prime}$ : Efektif örtü gerilimi $(\mathrm{kPa})$ 'dir.

$\mathrm{C}_{\mathrm{E}}=\mathrm{E}_{\mathrm{r}} / 60$

Zemindeki ince dane oranının artması sıvılaşmaya karşı döngüsel direnç oranını (CRR) arttırdığından, düzeltilmiş darbe sayıları $\mathrm{N}_{1(60)}$ değerinin zeminin ince dane oranına göre Denklem (7) ile tekrar düzeltilmesi önerilmektedir [6].

$$
\left(\mathrm{N}_{1}\right)_{60 \mathrm{cs}}=\alpha+\beta .\left(\mathrm{N}_{1}\right)_{60}
$$
göre belirlenir.

Bu eşitlikte ince dane yüzdesine (IDO) bağlı olarak $\alpha$ ve $\beta$ Denklem (8), Denklem (9) ve Denklem (10)'a

$$
\begin{aligned}
& \text { İO } \leq \% 5 \alpha=0, \beta=1.0 \\
& \% 5<\text { İO }<\% 35 \quad \alpha=\exp \left(1.76-\left(190 / \text { IDO }^{2}\right)\right), \beta=\left(0.99+\left(\mathrm{IDO}^{1.5} / 1000\right)\right) \\
& \text { İDO } \geq \% 35 \alpha=5.0, \beta=1.2
\end{aligned}
$$

$\mathrm{N}_{1(60)}$ değerinin 30'dan küçük olması durumu için, sıvılaşmaya karşı döngüsel direnç oranı (CRR) Denklem (11) ile hesaplanırken, 30'dan büyük olması durumunda zeminde sıvılaşma olmayacağı kabul edilir [6].

$$
C R R=\frac{1}{34-\left(N_{1}\right)_{60}}+\frac{\left(N_{1}\right)_{60}}{135}+\frac{50}{\left[10 \cdot\left(N_{1}\right)_{60}+45\right]^{2}}-\frac{1}{200}
$$

Deprem sırasında oluşan kayma gerilmelerinin, sıvılaşma direncini aştığı derinlikte FS $\leq 1$ olup sıvılaşma gerçekleşir. Aksi durumda sıvılaşma riski yoktur [1].

$$
F S=\frac{C R R}{C S R}
$$

İnceleme alanında beklenen moment magnitüdü cinsinden $\left(\mathrm{M}_{\mathrm{w}}\right)$ deprem büyüklüğüne göre güvenlik katsayısı (FS) Denklem (13) ve Denklem (14)'den hesaplanmaktadır [6].

$$
\begin{aligned}
& M S F=\frac{10^{2.24}}{M_{w}^{2.56}} \\
& F S=\frac{C R R}{C S R} M S F
\end{aligned}
$$




\section{SIVILAŞMA ANALİi̇}

Yeraltı su seviyesi yüzeye yakın, suya doygun, gevşek silt, siltli kum, kum, kumlu silt ve killi kum gibi zeminlerde sıvılaşma potansiyeli bulunmaktadır. Bununla birlikte kötü derecelenmiş veya üniform, efektif çap $\left(\mathrm{D}_{10}\right)$ değerinin $0.005-0.15 \mathrm{~mm}$ arasında olduğu zeminlerde, SPT-N değerlerinin yüzeye yakın kısımlarda 10'dan ve 20 m derinliğe kadar 20'den küçük olması durumunda, ince dane oranı \%15'ten daha az, Likit Limit değeri \%35’ten daha küçük düşük plastisiteli ve suya doygunluk derecesi yüksek olan zeminlerde sıvılaşma potansiyeli oldukça yüksektir. Bu faktörlerin yanında $20 \mathrm{~m}$ derinliğe kadar bir bölgede jeolojik efektif gerilmenin düşük olması sıvılaşma riskini arttırmaktadır.

Sıvılaşma duyarlılığının belirlenmesinde çalışma alanında 61 sondaj noktasından elde edilen SPT darbe sayıları kullanılmıştır. Çalışma alanında, yüzeyden itibaren $12 \mathrm{~m}$ derinliğe kadar sıvılaşma olasılığının dağılımını ve derinlikle değişimini görebilmek amacıyla 0-3 m, 3-6m, 6-9, 9-12 m derinlikleri için sıvılaşma analizleri yapılmış ve haritalar oluşturulmuştur. $\mathrm{Bu}$ analizlerde $N_{1(60)}$ değerlerinin 30 'dan büyük olması veya yeraltı su seviyesinin üstündeki bölgeler sıvılaşmaz olarak sınıflandırılmıştır. Mesafenin tersinir (MT) yöntemi ile SPT değerleri tahmini haritaları $10 \mathrm{~m}$ karelaj boyutlu olarak üretilmiş, hesaplamalara göre sıvılaşma riski bulunan bölgeler tespit edilmiştir. İnceleme alanında farklı derinlikler için sıvılaşma potansiyelini gösterir haritalar Şekil 7'de sunulmuştur.
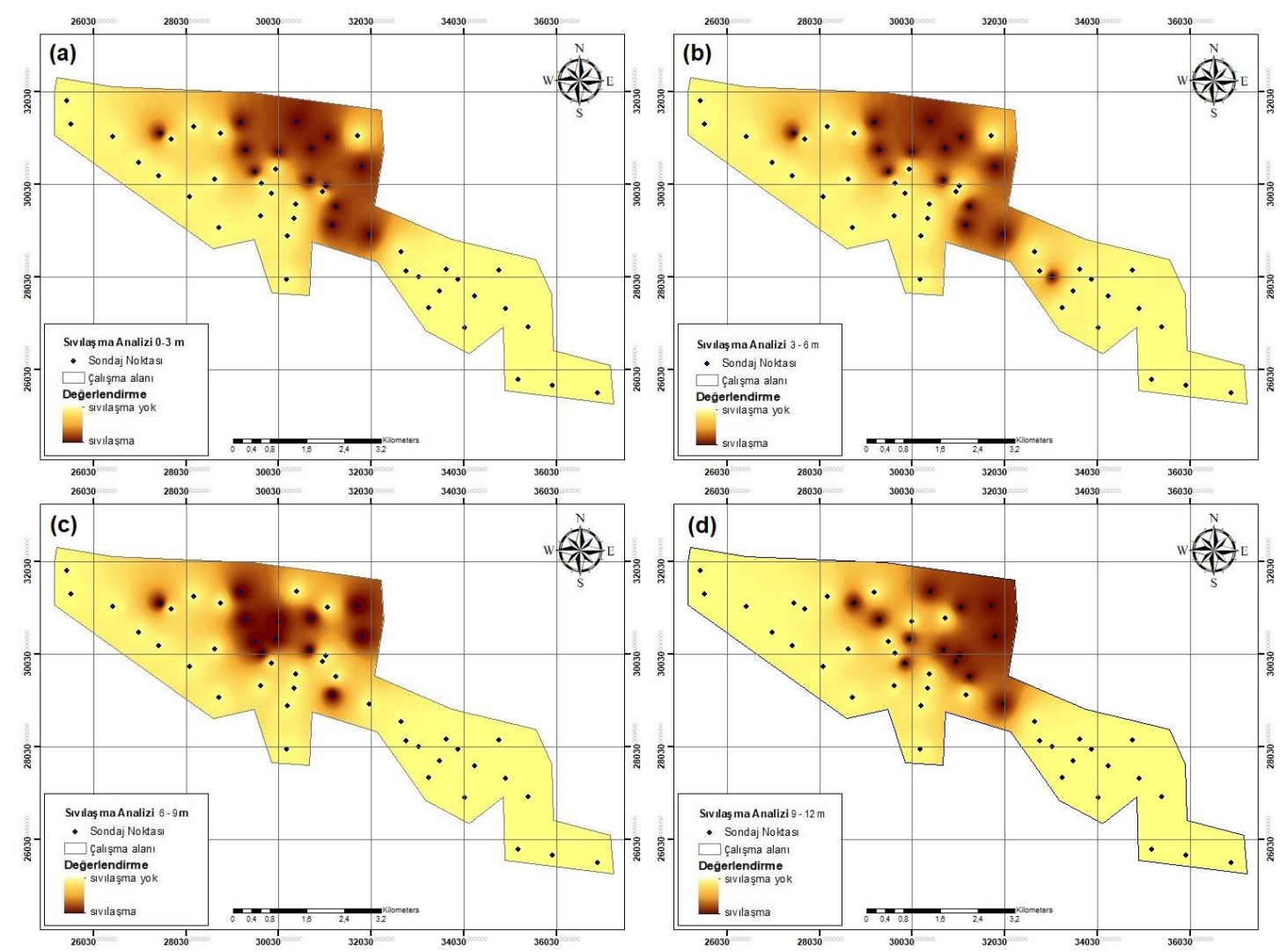

Şekil 7. (a) İnceleme alanında sıvılaşma potansiyelinin 0-3 m derinlikte değişimi, (b) 3-6 m derinlikte değişimi, (c) 6-9 m derinlikte değişimi, (d) 9-12 m derinlikte değişimi

Elde edilen sonuçlara göre 0-3 ve 3-6 m derinlikte çalışma alanı genelinde \%28'lik bir bölümün, 6-9 m derinlikte \%24'lük bir bölümün, 9-12 m derinlikte ise \%38'lik bir bölümün sıvılaşma riskinin bulunduğu tespit edilmiştir. Tüm inceleme derinliklerinde sıvılaşma potansiyelinin bulunduğu bölge yaklaşık olarak aynı olmakla birlikte bu bölge inceleme alanının kuzeybatı ucundan güneydoğu doğrultusunda birleştiren hattın kuzeyinde kalan kesimdir. Bu bölgede hakim zemin tipi derinlik boyunca benzer olup, siltli veya killi kum ve düşük veya orta plastisiteli silt zeminden oluşan gevşek alüvyonlardır. Yeraltı su seviyesi genellikle yüzeye yakın olup 1-5 m derinlikte yer almaktadır. SPT N değerleri 0-6 m aralığında 3-15 arasında değişirken çoğunlukla 10 değerinin altındadır. 6-9 ve 9-12 m derinlik aralığında sırasıyla 15-25 ve 7-40 arasında değerler almaktadır. Sıvılaşma 
bölgesinin güneyinde kalan alüvyon zeminin çok sıkı, katı sert zeminlerden oluştuğu veya yeraltı su seviyesinin çok derinde olmasından dolayı sıvılaşma potansiyelinin bulunmadığı belirlenmiştir.

\section{SONUÇLAR}

Türkiye'nin batısında Ege bölgesinde bulunan Kütahya ilindeki araştırma alanı, insan yoğunluğu olarak en fazla nüfusu barındıran ve yapı stoğu oldukça yüksek olan şehir merkezinde yer almaktadır. Kütahya ve Simav fay zonlarının etkisi altında olan inceleme alanı olası moment magnitüdü 6.5 değerinde ve $0.3 \mathrm{~g}$ yatay yer ivmesinde deprem senaryosu durumu için zemin türü, birim hacim ağırlık, ince dane yüzdesi, zeminin plastisite özellikleri, SPT-N değerleri ve yeraltı suyunun derinlikle değişimi gibi faktörler göz önünde tutularak sıvılaşma riski bakımından incelenmiştir. Sıvllaşma potansiyelinin belirlenmesi için T. L. Youd ve I. M. Idriss [6] metodunu kullanmıştır. Bu yöntem H.B. Seed ve I. M. Idriss [1] metoduna dayanır ve sıvılaşma potansiyelinin belirlenmesinde, zeminin sıvılaşmaya karşı güvenlik katsayısının tespit edilmesine dayanmaktadır [6]. Değerlendirmelerde söz konusu metod kullanılarak sıvılaşma riskine sahip alanlar tespit edilmiş ve 0-3 m, 3-6 m, 6-9 m, 9-12 m derinlikler için Coğrafi Bilgi Sistemi (CBS) yazılımları kullanılarak haritalar oluşturulmuştur. Üretilen haritalardan yapılan inceleme sonucunda, yaklaşık olarak inceleme alanında kuzeybatı ucundan güneydoğu doğrultusunda birleştiren hattın, kuzeyinde kalan kesimin SPT-N değerlerinin düşük ve aynı zamanda bu bölgede yeraltı su seviyesinin yüzeye yakın olduğu belirlenmiştir. Yapılan analizlere göre, sismik olarak aktif faylara yakın olan çalışma alanının Kuzeydoğusunda bulunan alüvyonlu bölgelerin Kütahya ovasına açıldığı kesimlerin sıvılaşma potansiyeli taşıldı̆̆ tespit edilmiştir. Bunun yanında sıvılaşma potansiyeline sahip olmayan alüvyon kesimlerin çok sıkı, katı-sert zeminlerden oluştuğu ve yapılan sondajlarda yeraltı suyunun çok derinde olduğu belirlenmiştir. Sıvılaşma analizleri kapsamında; Kütahya ilinde yapılan bu çalışmanın mevcut yerleşim alanlarının depremselliğinin değerlendirilmesinde, kentsel dönüşüm ve her türlü planlama faaliyetlerinde faydalı olacağı değerlendirilmektedir.

\section{TEŞEKKÜR}

Bu çalışmada, 2003 yılında hazırlanmış Afet İşleri Genel Müdürlüğü tarafından onaylanmış plana esas jeolojik-jeoteknik etüd raporu ve verilerinin kullanılmasına izin veren Kütahya Belediye Başkanı Prof.Dr. Alim Işık'a, İmar ve Şehircilik Müdürü Bahadır Halil Bahşi'ye, Mühendis Ahmet Haşimoğlu'na teşekkür ederiz.

\section{KAYNAKLAR}

[1] Seed, H. B., \& Idriss, I. M. (1971). Simplified procedure for evaluating soil liquefaction potential. Journal of the Soil Mechanics and Foundations Division, 97 (9), 1249-1273.

[2] Seed, H. B., \& Idriss, I. M. (1982). Ground motion and soil liquefaction during earthquakes. Earthquake Engineering Research Institute Monograph Series, Oakland, CA, USA, 134.

[3] Seed, H. B., Tokimatsu, K., Harder, L. F., \& Chung, R. M. (1985). The influence of SPT procedures in soil liquefaction resistance evaluations. J. Geotech. Eng.-ASCE, 111 (12), 1425-1445.

[4] Cetin, K. O., Seed, R. B., Der Kiureghian, A., Tokimatsu, K., Harder, L. F., Kayen, R. E., et al. (2004). SPTBased probabilistic and deterministic assessment of seismic soil liquefaction potential. J.Geotech. Geoenviron. Eng.-ASCE, 130 (12), 1314-1340.

[5] Tosun, H., Seyrek, E., Orhan, A., Savaş, H., \& Türköz, M. (2011). Soil liquefaction potential in Eskisehir, NW Turkey. Natural Hazards and Earth System Sciences, 11 (4), 1071-1082.

[6] Youd, T. L., Idriss, I. M., Andrus, R. D., Arango, I., Castro, G., Chrstian, J. T., et al. (2001). Liquefaction resistance of soils, Summary report from the 1996 NCEER and 1998, NCEER/NSF workshop on evaluation of liquefaction resistance of soils, Journal of Geotechnical and Geoenvironmental Engineering, -ASCE. 127 (10), 817-833.

[7] Ayhan, E. (1988). Türkiye'de 1881-1988 yılları arasında oluşmuş şiddetli depremler. Deprem Araştırma Bülteni, 61.

[8] Afet İşleri Genel Müdürlüğü tarafindan onaylanmış, Kütahya Belediyesinin plana esas jeolojik-jeoteknik etüd raporu. 2003.

[9] Afet ve Acil Durum Yönetimi Başkanlığı Deprem Dairesi Başkanlığı. (2020). Deprem Kataloğu, https://deprem.afad.gov.tr/depremkatalogu.

[10] Liao, S., \& Whitman, R. V. (1986). Overburden correction factors for SPT in sand. J. Geotech. Eng.-ASCE, $112(3), 373-377$. 